Neuroepidemiology 2010;35:213

DOI: $10.1159 / 000313554$

\section{What Is the Clinical Significance of the Findings from the Delayed-Start Trial of Rasagiline in Parkinson's Disease?}

Nicola Vanacore

National Centre for Epidemiology, Surveillance, and Health Promotion, National Institute of Health, Rome, Italy

The delayed-start randomized clinical trial (RCT) design was introduced to address the question of symptomatic or neuroprotective effects of a drug for diseases that progress slowly such as Alzheimer's disease and Parkinson's disease (PD) [1].

In this study design, patients are randomly assigned to study either a drug or a placebo in the first phase of the study, and both groups receive the active drug in the second phase. If benefits seen at the end of the first phase persist through the end of the second phase, they cannot be readily explained by a symptomatic effect and benefits in the early-start group must relate to the early initiation of the treatment.

There is only one study which is available so far: a doubleblind, delayed-start trial of rasagiline in PD [2]. I believe that this issue is very important for the future of clinical research in the field of neurodegenerative diseases and I would like to propose a new reflection on the results of this study beyond the comments that have already been published $[3,4]$.

In this RCT a difference of 1.7 points in the Unified Parkinson's Disease Rating Scale (UPDRS) score between the early-start group and the delayed-start group receiving a dose of $1 \mathrm{mg}$ rasagiline per day has emerged after 72 weeks, while early treatment with a dose of $2 \mathrm{mg}$ rasagiline per day has not shown any difference.

A post hoc subgroup analysis in patients with UPDRS scores in the highest quartile at baseline ( $\geq 25.5$ points) showed that subjects who received a dose of $2 \mathrm{mg}$ rasagiline per day in the earlystart group had less worsening in the UPDRS between baseline and week 72 than patients in the delayed-start group $(\mathrm{p}=0.04)$.

The authors hypothesized that the effects on symptoms associated with the 2-mg dose per day may have masked a diseasemodifying effect in PD patients with very mild disease.

The authors declared that results were consistent with a possible disease-modifying effect of rasagiline. This is the first RCT that could introduce a disease-modifying drug in the clinical practice of neurodegenerative diseases. I have some doubts on this RCT:

(1) The UPDRS scale ranges from 0 to 176 and includes subscales of mental function, activities of daily living, and motor function. Although the authors declared that the clinical significance of a difference of 1.7 points is not known, they did not report the RCT results for each UPDRS subscale.

(2) The 1,176 patients included in the RCT were recruited from 129 centres in 14 countries. No inter-rater reliability measure in the use of UPDRS was reported.
(3) The post hoc analysis has a secondary value in the RCT. The authors do not mention if a correction for multiple comparisons of the $\mathrm{p}$ value was performed in the post hoc analysis. The authors of the ADAGIO trial do not comply with the Guidelines for Reporting Subgroup Analysis recommended by Wang et al. [5].

(4) The possibility that rasagiline might have a neuroprotective effect at a 1-mg dose per day and might not have this kind of effect at a 2-mg dose per day is not mentioned.

In conclusion, I would like to mention that the European Medicine Agency and the US Food and Drug Administration did not approve rasagiline as a disease-modifying drug.

The scientific community discusses about the preclinical phase of PD (a variety of non-motor symptoms can precede the classic motor features of PD by years and, perhaps, even decades) [6-8].

I fear that the uncertain results of the ADAGIO study and several ways in which the results have been shown in the article (i.e. the UPDRS scores reported as mean and standard error and not as mean and standard deviation; the effect of rasagiline at the 1 -mg dose that represents a $38 \%$ reduction in the degree of change from baseline) can contribute to promote in the clinical practice an off-label use of rasagiline.

Moreover, from the point of view of public health, head-tohead RCTs on the efficacy and safety of rasagiline versus selegiline in PD are not available. I believe that further RCTs in accordance with this interesting design should be performed in the field of neurodegenerative diseases.

\section{References}

$\checkmark 1$ D’Agostino RB Sr: The delayed-start study design. N Engl J Med 2009; 361:1304-1306.

2 Olanow CW, Rascol O, Hauser R, Feigin PD, Jankovic J, Lang A, Langston W, Melamed E, Poewe W, Stocchi F, Tolosa E, ADAGIO Study Investigators: A double-blind, delayed-start trial of rasagiline in Parkinson's disease. N Engl J Med 2009;361:1268-1278.

3 Kieburtz K: ADAGIO misses a beat? Lancet Neurol 2009;8:1081-1082.

4 Youdim MB, Schwarzschild MA, Olanow CW, Rascol O: Rasagiline in Parkinson's disease. N Engl J Med 2010;362:657-659.

5 Wang R, Lagakos SW, Ware JH, Hunter DJ, Drazen JM: Statistics in medicine-reporting of subgroup analyses in clinical trials. N Engl J Med 2007;357:2189-2194.

$\checkmark 6$ De Lau LM, Koudstaal PJ, Hofman A, Breteler MM: Subjective complaints precede Parkinson disease: the Rotterdam study. Arch Neurol 2006;63:362-365.

7 Postuma RB, Gagnon JF, Vendette M, Fantini ML, Massicotte-Marquez J, Montplaisir J: Quantifying the risk of neurodegenerative disease in idiopathic REM sleep behavior disorder. Neurology 2009;72:1296-1300.

$\checkmark 8$ Tolosa E, Gaig C, Santamaría J, Compta Y: Diagnosis and the premotor phase of Parkinson disease. Neurology 2009;72(suppl 7):S12-S20.

Nicola Vanacore, MD, PhD

National Centre for Epidemiology, Surveillance, and Health Promotion National Institute of Health

Via Giano della Bella 34, IT-00161 Rome (Italy)

Tel. +39 064990 4243, Fax +390649904248

E-Mail nicola.vanacore@iss.it

\section{KARGER}

Fax +41 613061234 E-Mail karger@karger.ch www.karger.com
C 2010 S. Karger AG, Basel

0251-5350/10/0353-0213\$26.00/0 